\title{
CONCEPÇÕES DE EDUCAÇÃO E JUSTIÇA: articulação possível com a gestão democrática da escola'
}

\author{
Dinair Leal da Hora²
}

A narrativa da justiça foi, e ainda é hoje, objeto de interpretações várias e conflituantes. Assim, ela foi interpretada como: tolerância, lei natural ou direitos naturais; como utilidade ou como respeito pela pessoa; como equidade, imparcialidade e liberdade igual; como igualdade jurídica ou como igual respeito e consideração; como capacidade ou possibilidade de realização daquilo que cada um valoriza, entre muitas outras definições (ESTEVÃO, 2004).

\section{INTRODUÇÃO}

Após longo período pesquisando, orientando mestrandos e doutorandos e publicando sobre a temática da gestão democrática, durante a realização de um pós-doutoramento na Universidade do Minho, em Portugal, tive a oportunidade de participar da discussão realizada pelo Prof. Dr. Carlos Vilar Estevão, na disciplina que ministrava para as turmas de Mestrado em Ciências da Educação no Instituto de Educação a qual tratava de Educação e Justiça.

Como para mim era um tema novo, passei a realizar as leituras indicadas pelo Dr. Estevão e fui buscar outras leituras para me apropriar dos

1 Conferência apresentada no I CICLO DE CONVERSAS, evento organizado pela Coordenação do Programa de Pós-Graduação em Educação na Amazônia - Associação em Rede na Universidade Federal do Pará, em abril de 2020.

2 Doutora em Educação pela Universidade de Campinas (UNICAMP). Professora Adjunta da Universidade Federal do Pará (UFPA) - Campus de Abaetetuba e professora Permanente do Programa de Pós-Graduação em Currículo e Gestão da Escola Básica (PPEB/UFPA) e do Doutorado em Rede em Educação na Amazônia. Orcid iD: 0000-0002-3278-3914. E-mail: tucupi@uol.com.br 
conceitos fundantes da articulação que se estabelece entre educação e justiça, como escola justa, justiça complexa, justiça radical, entre outros e, assim, tentar construir uma aproximação possível com a gestão democrática.

Quando retornei ao Brasil, apresentei os resultados desses estudos para os mestrandos do Programa de Pós-Graduação em Educação, Comunicação e Cultura da UERJ e ofereci o tema de pesquisa Educação e Justiça, recebendo quatro novos orientandos que pesquisaram a respeito de escola justa.

A abordagem do conceito de justiça, que a retira do sentido jurídicoformal, incluindo-a no sentido eminentemente político, ético, filosófico, cultural e sociológico, permite compreender sua relação orgânica com os conceitos de igualdade, equidade, liberdade, mérito, poder, autoridade, entre outros, que condicionam, de modo particular, a maneira como pensamos a educação e a forma como as escolas se organizam para cumprirem suas finalidades.

Assim, quero estabelecer com todos que me ouvem agora, uma discussão a respeito de Educação e Justiça, tendo como objeto as concepções de justiça.

\section{ALGUMAS APROXIMAÇÕES COM AS CONCEPÇÕES DE JUSTIÇA}

As concepções que se tem acerca de justiça são tão diversas quanto os princípios utilizados para defini-la. Estêvão (2004) debruça-se nas diferentes abordagens de justiça, procurando organizá-las de acordo com três perspectivas: a universalista, a pluralista e, a radical.

$\mathrm{Na}$ perspectiva universalista podemos localizar a Justiça (Re) Distributiva, sistematizada por John Rawls (2008) e considera que uma sociedade bem ordenada é aquela na qual existem mecanismos compensatórios e regulatórios legais, capazes de diminuir as desigualdades econômicas e igualar as oportunidades de emprego.

Na perspectiva pluralista encontramos a Justiça Variável ou Plural, cujo principal representante é Michael Walzer (2003) para quem a justiça será 
diferente a partir do contexto social tratado; um bem jurídico com um estimado valor naquela sociedade, poderá ser elevado ao status de "direitos fundamentais" e ter uma estabilidade constitucional rígida.

Já a perspectiva radical critica às perspectivas universalista e pluralista, trazendo para o centro a concepção de justiça social como repartição de bens materiais e distribuição de posições sociais; quando se estende aos bens sociais imateriais - poder de decisão, oportunidade e respeito próprio -, eles passam a ser representados como "coisas estáticas", em vez de processos que regem as relações sociais. Iris Young (1990), Nancy Fraser (2007) e François Dubet (2004) são os principais representantes da perspectiva radical de justiça.

Após essa breve caracterização, vou seguir procurando aprofundar um pouco mais as ideias defendidas por cada um dos autores em cada uma das perspectivas classificadas por Estevão (2004).

A teoria (re)distributiva da justiça de Rawls costuma ser rotulada como liberal e igualitária: liberal porque pretende garantir a tolerância e a liberdade individual; igualitária porque valoriza a igualdade econômica e social.

Afirma Rawls (2008): primeiro: cada pessoa deve ter um direito igual ao sistema mais extenso de iguais liberdades fundamentais, que seja compatível com um sistema similar de liberdades para outras pessoas. Segundo: as desigualdades sociais e econômicas devem estar dispostas de tal modo que tanto (a) se possa razoavelmente esperar que se estabeleçam em benefício de todos como (b) estejam vinculadas a cargos e posições acessíveis a todos.

Rawls pretende tratar as pessoas como iguais sem remover todas as desigualdades, mas apenas aquelas que trazem prejuízo a alguém. Se alguém, utilizando, por exemplo, seu talento, beneficia de alguma forma a todos, a desigualdade resultante é permitida.

Sobre o princípio da liberdade igual, Rawls afirma que todas as pessoas devem possuir um sistema de liberdades básicas e de direitos iguais para todos, na qual este programa, para sua plena e satisfatória existência, deva 
ser compatível com os programas de direitos e liberdades de outros indivíduos.

Assim, Rawls busca dizer que existem certos direitos e liberdades que devem ser privilegiados em detrimento de outros direitos e liberdades existentes em sociedade.

As liberdades básicas segundo Rawls (2008) devem ser de outros direitos e liberdades existentes em sociedade e compreendidas como a liberdade política (direito ao voto e a exercer cargo púbico), a liberdade de expressão e de reunião, a liberdade de consciência e de pensamento, a liberdade individual, que compreende a proteção contra a opressão psicológica, a agressão e a mutilação (integridade da pessoa) o direito à propriedade pessoal e a proteção contra prisão e detenção arbitrárias, segundo o conceito de Estado de Direito. O primeiro princípio estabelece que essas liberdades devem ser iguais.

Quanto ao princípio da oportunidade justa e o princípio da diferença Rawls teoriza que quando as pessoas estiverem em condições iguais deverão ter acesso às mesmas chances. Desse modo, as desigualdades econômicas e sociais devem estar ligadas a postos e posições acessiveis a todos em condições de igualdade de oportunidades. Contudo, neste princípio a desigualdade na oportunidade pode ser permitida se ela beneficiar os menos favorecidos. Logo, o Estado deve ajudar mais os que necessitam, ou seja, o Estado deve dar mais oportunidades para os menos privilegiados, para que estes possam ter acessos aos bens primários. Sendo assim, seguindo esses princípios para reestruturar a sociedade conseguiremos torná-la justa.

Rawls (2008) atribui a esses princípios uma escala de prioridade: o primeiro tem prioridade sobre o segundo; e a primeira parte do segundo (a) tem prioridade sobre a segunda parte (b) o que permitiria a coexistência de diferentes modos de vida.

Com visões antagônicas às posições universalistas, a perspectiva pluralista propõe a justiça de forma mais contextualizada, ligada a uma comunidade política concreta - com tradição comum e significados sociais 
comuns, podendo ser específica de cada esfera social - como na educação, no trabalho, na saúde, etc.

Como afirma Tavares (2009) não há como se estabelecer uma teoria de justiça fundamentada em princípios imparciais e universais, muito menos na existência de indivíduos abstratos, sem raízes, livres de qualquer influência histórica ou cultural, conforme defendido pela teoria da justiça de John Rawls, para quem os indivíduos devem escolher os princípios de justiça protegidos pelo "véu da ignorância", ou seja, privados de suas próprias personalidades, contingências históricas e ignorância", ou seja, privados de suas próprias personalidades, contingências históricas e concepções particulares acerca da vida digna.

Michael Walzer, tido como o autor mais representativo desta corrente considera que toda a sociedade é uma comunidade distributiva, na qual a dominação se exerce frente à forma como se utilizam dos bens sociais e, assim, uma determinada sociedade só será justa se a sua vida for vivida de uma maneira fiel às compreensões partilhadas dos seus membros e que, portanto, qualquer demonstração da justiça distributiva será sempre uma explicação local.

A teoria de justiça de Walzer começa com a afirmação de que os homens vivem em uma comunidade distributiva, portanto, a ideia de justiça social tem a ver não só com a produção e o consumo, mas também com o processo de distribuição dos bens sociais. Para Walzer, essa distribuição não é simples. Isso porque não há apenas um bem social, assim como não há apenas um critério de distribuição ou um único agente distribuidor.

Muito pelo contrário, a vida em comunidade revela um vasto rol de bens sociais, com diferentes agentes distribuidores e diferentes critérios de distribuição. Assim, para Walzer, qualquer sistema distributivo que não levar em consideração essa complexidade de fatores não conseguirá alcançar a realidade da pluralidade humana. Além disso, a escolha dos princípios que regulam esse sistema distributivo deve ser feita levando se em consideração - particularismo de cada comunidade, suas características históricas e culturais (TAVARES, 2009). 
Assim, Walzer propõe uma sociedade organizada em esferas que possuem características e necessidades próprias e têm os seus próprios critérios de distribuição. É a igualdade complexa de Walzer. Por isso, é justo que a distribuição das diferentes oportunidades e dos diferentes bens sociais como segurança, bem-estar, educação, dinheiro, trabalho, tempo livre, poder político, amizade, igualdade seja feita de acordo com a necessidade, o mérito e o mercado de cada um desses mundos.

Então, podemos compreender uma teoria pluralista da justiça social como uma proposição, cuja meta é realizar a "igualdade complexa", que é, segundo Estevão (2004) entendida como aquela que respeita a liberdade e que exige a distribuição dos bens sociais segundo uma diversidade de procedimentos e critérios (tais como a necessidade, o mérito e o mercado), ou seja, de acordo com o significado do bem social em causa.

Walzer afirma ainda que a vida social consiste, fundamentalmente, em organizar compromissos entre vários mundos ou 'grandezas' que aí se constituem e que corporizam formas de bem comum. Os diferentes mundos apontam definições próprias para justiça.

A esse respeito Estêvão (2004) exemplifica com a indicação de seis mundos a saber:

a) o mundo doméstico tende a apelar para uma justiça familiar;

b) já o mundo cívico é a ética da justiça: argumentação racional, sem coações e onde as dimensões da solidariedade, da igualdade e do interesse público prevalecem;

c) no mundo industrial a justiça é articulada com a performance, com os procedimentos corretos visando à produtividade;

d) no mundo mercantil a justiça é vinculada à ideia de justeza dos preços, do respeito pelos acordos e concorrências, do respeito pela propriedade privada;

e) a justiça do mundo da inspiração decorre da singularidade e criatividade;

f) a justiça do mundo da opinião é a justa reputação e opinião dos outros. 
Nesta mesma corrente, nos sãos apresentados autores como Boltanski \& Thévenot (1991), que falam do mesmo pluralismo, tendo sua gênese nas estratégias de justificação do mesmo pluralismo, concretizadas pelos atores sociais, no entanto, em situação de conflito ou controvérsias.

O avanço dos estudos e discussões a respeito das concepções de justiça resultou na construção da perspectiva radical com seus principais organizadores e defensores: Young (1990); Fraser (2007) e Dubet (2002).

Young (1990) traz para a discussão as categorias opressão e dominação ao considerar que a justiça tem como objetivo a eliminação da dominação e da opressão, no âmbito dos processos de tomada de decisão, da divisão do trabalho e cultura é, conforme interpreta Estêvão (2004, p.30) "interessada numa política valorizadora da diferença". Assim, a autora afirma que este modelo distributivo defendido nas perspectivas universalista e pluralista é o reforço da injustiça pela universalização das normas dos grupos dominantes a partir de políticas de distribuição que são cegas à diferença.

Young considera a opressão como processos institucionais sistemáticos que impedem algumas pessoas de aprender e usar habilidades expansivas e satisfatórias em cenários socialmente reconhecidos ou processos socialmente institucionalizados; inibem as habilidades das pessoas de agir e comunicar-se umas com as outras ou expressar seus sentimentos e perspectiva de vida social em contextos onde outros possam ouvir.

A autora indica, ainda quais são as faces da opressão: Exploitation (exploração); Marginalization (marginalização); Powerlessness (ausência de poder); Cultural imperialism (imperialismo cultural) e Violence (violência).

Já a dominação consiste em condições institucionais que inibem ou impedem as pessoas de participar na determinação ou condição de suas ações. As pessoas vivem dentro de estruturas de dominação quando outras pessoas ou grupos podem determinar, sem reciprocidade, as condições de suas ações, quer diretamente, quer em virtude das consequências estruturais de suas ações e aposta que a melhor maneira de combater as distorções institucionais do processo deliberativo é assegurar que grupos subalternos 
possam formular, autonomamente, seus interesses em uma sociedade marcada pelas diversas "faces" de opressão: (1) auto-organização; (2) análise do grupo e geração de propostas e (3) poder de veto sobre as políticas específicas (YOUNG, 1990).

Deste modo, as políticas públicas devem enfraquecer a opressão dos grupos, afirmando sua diferença. Os grupos oprimidos, como as mulheres, os negros, os índios e, os homossexuais, por exemplo, devam ser representados, politicamente, aprovando e fazendo cumprir uma legislação, de modo a garantir que seus direitos não sejam desrespeitados.

Nancy Fraser (2007) que também está incluída na perspectiva radical incorpora a educação e a escola na discussão das concepções de justiça e considera a justiça como o aprofundamento de suas raízes democráticas e participativas, combatendo por maior simetria estrutural de poder, nos diferentes níveis de relações sociais (relações de trabalho, organizações, interações, tomada de decisões...); defende a ausência de dominação cultural, não reconhecimento e desrespeito.

Melhor que tentar afirmar, os direitos dos grupos oprimidos de modo a serem tratados igualmente, Fraser advoga estratégias transformadoras que envolvem a desconstrução de categorias sociais existentes e a reconstrução radical das relações de produção.

Fraser (2007), com sua justiça de paridade participativa ou de associação, defende a afirmação do papel educativo e cultural da escola não apenas ao nível da instrução, mas também nas atividades culturais e desportivas, na organização da própria vida escolar, no atendimento dos alunos fora da classe. No caso dos professores, a dignificação de seu trabalho, a garantia do respeito pelas suas idiossincrasias e a valorização de seus saberes e fazeres.

Fraser afirma que hoje, o raciocínio assenta-se não tanto em termos de igualdade, mas, antes em parâmetros de custo e eficácia, de maximização da eficiência mercantil, independentemente dos efeitos de exploração, competição e desigualdade que geram, acolhendo, pacificamente a ideia, por exemplo, de que é exigência de progresso a separação entre o 
econômico e o social, devendo pugnar se, simultaneamente pela integração econômica e pela desintegração social.

Ao mesmo tempo, os atuais movimentos de globalização levam-nos a colocar na ordem do dia a questão da justiça, uma vez que também aqui assistimos ao fato da argumentação sobre a justiça está a alterar-se, salientando a pluralidade de sentidos, consoante as várias definições, perspectivas e teorias sociais de que partimos, ao mesmo tempo que se exige um outro paradigma, o da "justiça democrática pós Westfaliana" (FRASER, 2007).

Para completar a relação dos três principais pensadores que se alinham à perspectiva radical, trago François Dubet (2002) e sua justiça complexa, para repensar a justiça da escola é ir à procura de novas articulações entre princípios e realidades, destaque especial à educação e à escola.

Dubet discute o conceito de justiça, no sentido eminentemente político, ético, cultural e sociológico, que assume íntima relação com os conceitos de igualdade, equidade, liberdade, mérito, poder, autoridade, entre outros, que condicionam, de modo particular, a maneira como pensamos a educação e a forma como as escolas se organizam para cumprirem suas finalidades.

Neste sentido, o contributo da noção de "justiça complexa" lou dos vários princípios de justiça) permite, desde logo, questionar a pertinência do conceito unívoco de justiça escolar, que, sob a forma de equidade formal e universal (e que tende a definir se como o critério de cada um receber de acordo com a sua contribuição), reproduz de fato, embora de forma velada, uma pluralidade de formas de injustiça.

Por outro lado, a escola é compreendida como uma organização plural, como uma arena de plurirracionalidades, de coordenação, de princípios argumentativos, de lógicas compósitas de justificação, ou de concepções plurais de justiça, obrigando por isso os atores educativos a coordenarem as suas ações, resolvendo os seus conflitos e dissensos locais, aprendendo, enfim, a passar de um sistema de referência ou de justificação 
para outro, a negociar interpretações diferentes da realidade escolar para que a escola, apesar de tudo, funcione com normalidade ou, pelo menos, dentro de regras mínimas de convivência e de uma coerência aceitável (DUBET, 2002).

Isto reforça a ideia de que os sujeitos escolares estejam, por um lado, despertos para um trabalho incessante e contínuo de justificação e de construção permanente deles mesmos no sentido de se tornarem verdadeiramente sujeitos, e, por outro, que estejam preparados para a negociação sobre a definição legítima da, verdadeiramente, sujeitos e, por outro, que estejam preparados para a negociação sobre a definição legítima da situação, tendo em vista a construção política de acordos ou de compromissos, assim como para a compreensão da situação, tendo em vista a construção política de acordos ou de compromissos, assim como para a compreensão dos mecanismos de produção de novos mecanismos de produção de "novas legitimidades educativas". Assim sendo, a ação organizacional escolar se explica não apenas pela socialização, mas também, pela economia das "razões práticas" ou das "boas razões" que reenviam, entre outros aspectos, as lógicas de comunicação contextualizadas (DUBET, 2002).

Segundo Dubet a justiça na educação é relacionada, fundamentalmente, com o princípio da igualdade de oportunidades, com o mérito, com o respeito e, até, mais recentemente, com a eficiência, com a qualidade e com a competição. Considerar o princípio singular da igualdade de oportunidades, de inspiração liberal, na atualidade, revela uma tendência restritiva, já que este princípio acentua a função da escola de fornecer oportunidades e não satisfações, aberturas limitadas e não direitos inalienáveis.

Num contexto em que há prevalência da lógica de mercado, o princípio da igualdade de oportunidades é um meio para deformar o próprio princípio da igualdade educativa, pois como mecanismo de legitimação das desigualdades, objetivamente, justifica a desigualdade na obtenção de outros benefícios a que a educação dá acesso (emprego, por exemplo). 
Segundo Gewirtz (2006), essa concepção relacional de justiça pode aplicar-se às políticas educativas, já que elas podem apoiar, interromper ou subverter:

a) as relações de exploração nas escolas e fora das escolas, visíveis nas estruturas e práticas que podem produzir interações sociais baseadas em pressupostos classistas, racistas, sexistas, etc.;

b) os processos de marginalização e inclusão nas escolas e noutros contextos;

c) a promoção de relações baseadas no reconhecimento, respeito, cuidado e mutualidade, ou o enfraquecimento do poder de alguns sujeitos e/ou grupos;

d) as práticas violentas no sistema escolar e fora dele.

Apresentados os diversos conceitos, verificamos que a justiça está correlacionada às questões igualdade e liberdade. Estes conceitos, embora amplos, norteiam as ações humanas a partir de valores socialmente desenvolvidos que foram amplamente debatidos e aceitos racionalmente pela sociedade. Porém, na atualidade da sociedade brasileira, percebemos que a esfera da justiça vem sendo ferida com a permanência e a ampliação das desigualdades.

\section{CONSIDERAÇÕES EM PROCESSO}

As concepções que se tem acerca de justiça são tão diversas quanto os princípios utilizados para defini-la. Assim, por exemplo, há autores que defendem a perspectiva universalista, que afirma que ser justo é tratar da mesma forma os seres que são iguais em certo ponto de vista, que possuem uma mesma característica, a única que se deve levar em conta na administração da justiça, afirmando que uma sociedade pode ser considerada justa quando todos os cidadãos adotam a mesma concepção de justiça, atuando conforme os princípios aceitos por todos como justos.

Entretanto, alguns autores, contrariando as posições universalistas, defendem a justiça sob as perspectivas pluralista e radical como Walzer, 
Young, Fraser e Dubet, compreendem a justiça de forma mais ampla, societária e inclusiva.

Da minha parte, com 0 permanente estudo a respeito das concepções de educação e justiça venho encontrando articulação orgânica da justiça com a participação democrática na gestão escolar na crença de que esta é a via mais legítima para a melhoria da qualidade do ensino, da consciência crítica da realidade social para a construção de uma escola verdadeiramente pública, do bem comum. Justa.

Muito obrigada.

\section{REFERÊNCIAS}

BOLTANSKI, L.; THÉVENOT, L. De la justification economies de la grandeur. Paris, Gallimard, 1991.

DUBET, F. As Desigualdades Multiplicadas. ljuí/RS: Ed. Unijuí, 2003.

DUBET, F. Le déclin de l'in stitution. Paris: Seuil, 2002.

DUBET, F. Les Places et les chances. Repenser la justice sociale. Paris: La République de Idées/Sevil, 2010.

DUBET, F. O que é uma escola justa? A escola das oportunidades. São Paulo: Cortez, 2008.

DUBET, F. O que é uma escola justa? Cadernos de Pesquisa, vol. 34, n. 123, p. 539--555, 2004.555, 2004. Disponível em Disponível em: http://www.scielo.br/scielo.http://www.scielo.br/scielo.

ESTEVÃO, C. A. V. Educação, justiça e democracia: um estudo sobre as geografias da justiça em educação. São Paulo: Cortez, 2004.

FRASER, N. JUstiça anormal. Revista da Faculdade de Direito da Universidade de S. Paulo, v. 108, jan./dez. 2013, p. 739768.

FRASER, N. Justice Interruptus: Critical Reflections on the "Postsocialist" Condition. Cambridge: Routledge, 1997.

FRASER, N. Reenquadrando a justiça em um mundo globalizado. Lua Nova [online]. 2009, n.77, p. 11 39. ISSN 0102 6445. doi: 10.1590/S0102 64452009000200001 .

FRASER, N. Reframing justice in a globalizing world. D. Held \& A. Kaya (Eds.), Global Inequality. Cambridge: Polity Press, 2007, p. 252272. 
GEWIRTZ, S. Towards a contextualized analysis of social justice in education. Educational Philosophy and Theory 1, (1), 2006. p.69-81.

RAWLS, J. Uma teoria da justiça. 3 ed. São Paulo: Martins Fontes, 2008.

WALZER, M. Esferas da justiça: uma defesa do pluralismo e da igualdade. São Paulo: Martins Fontes, 2003.

TAVARES, F. C. Michael Walzer e as Esferas da Justiça. Trabalho publicado nos Anais do XVIII Congresso Nacional do CONPEDI, São Paulo novembro de 2009.

YOUNG, I. M. "Deferring group representation". In: SHAPIRO e KYMLICKA (Orgs.). Ethinicity and group rights (Nomos 39), 1997.

YOUNG, I. M. Justice and the politics of difference. Princeton: Princeton University Press, 1990.

Recebida em: 10 de setembro de 2020 Aprovada em: 06 de novembro de 2020

Publicada em: 13 de janeiro de 2021 